American Journal of Pharmaceutical Education 2018; 82 (9) Article 6452.

\title{
RESEARCH
}

\section{Implementation of a Medicare Plan Selection Assistance Program Through a Community Partnership}

\author{
Lindsey A. Hohmann, PharmD, ${ }^{\text {a }}$ Tessa J. Hastings, MS, , Stuart J. McFarland, BE, ${ }^{a}$ \\ Joshua C. Hollingsworth, PharmD, PhD, ${ }^{b}$ Salisa C. Westrick, $\mathrm{PhD}^{\mathrm{a}}$ \\ ${ }^{a}$ Harrison School of Pharmacy, Auburn University, Auburn, Alabama \\ ${ }^{\mathrm{b}}$ Edward Via College of Osteopathic Medicine-Auburn, Auburn, Alabama \\ Submitted April 7, 2017; accepted May 8, 2017; published November 2018.
}

\begin{abstract}
Objective. To describe the implementation and outcomes of a sustainable Medicare Plan Selection Assistance Program conducted through a partnership between Auburn University Harrison School of Pharmacy (AU) and the Alabama State Health Insurance and Assistance Program (SHIP) since 2013. Methods. The program's goal is to assist Medicare beneficiaries in Medicare Part D plan selection. Reported outcomes included Medicare beneficiaries' plan cost savings and satisfaction, and pharmacy students' self-reported changes in knowledge and attitudes.

Results. Each year, more than 80 pharmacy students assist more than 120 beneficiaries; at least 10 events are held covering 6-10 Alabama counties. On average, Medicare beneficiaries had a projected savings of \$278.71 (2013), \$1,081.66 (2014), \$842.84 (2015), and \$1,382.90 (2016) after enrolling in a new plan, and most students reported perceived increased ability to help beneficiaries select the most appropriate Medicare Part D plan.

Conclusion. The program produced positive outcomes for both beneficiaries and students. Other pharmacy schools may consider partnering with their State Health Insurance and Assistance Program to deliver a similar program to benefit their students and Medicare beneficiaries.

Keywords: Medicare, plan selection, pharmacy students, community outreach, State Health Insurance and Assistance Program
\end{abstract}

\section{INTRODUCTION}

Medicare is a beneficial and far-reaching program, but many patients still struggle to enroll and understand their coverage. Medicare insurance plans provide medical and prescription benefits to over 55 million seniors and disabled individuals. ${ }^{1}$ In 2015, over 37 million individuals were enrolled in the Medicare Part D prescription drug benefit. ${ }^{2}$ The Medicare Plan Finder Tool available at Medicare.gov is the primary access point for Medicare plan selection and enrollment; however, beneficiaries report difficulty with using the tool. ${ }^{3,4}$ Furthermore, many beneficiaries do not reevaluate their plans annually, and many eligible individuals do not enroll in the most appropriate plan for them, due to confusion regarding the multitude of plans available. ${ }^{3,5}$ In 2015, there were over 1,000 standalone Prescription Drug Plans (PDPs) offered throughout the United States, with an average of 30 per

Corresponding Author: Salisa C. Westrick, Harrison School of Pharmacy, 020 James E. Foy Hall, Auburn University, Auburn, AL 36849. Tel: 334-844-8314. Fax: 334-844-8307. E-mail: westrsc@auburn.edu region. $^{2}$ To decide on the best of these plans, Medicare beneficiaries must weigh multiple factors, including (but not limited to) pharmacy access, formulary restrictions, and co-pay and premium costs. ${ }^{6,7}$ This complexity results in patients paying higher out-of-pocket costs than necessary. ${ }^{3,8,9}$ Indeed, past research shows that older adults with lower numeracy and health literacy skills are less likely to choose cost-minimizing plans and are less aware of and less likely to apply for cost-saving Medicare subsidy programs, ${ }^{10,11}$ which is compounded by the complex plan selection landscape. ${ }^{12,13}$ In light of these challenges, previous initiatives, including the National Medicare Education Program (NMEP) ${ }^{14}$ and the Choose with Care System, ${ }^{15}$ have used simplified educational materials such as handbooks and interactive websites to assist Medicare beneficiaries in plan selection.

One-on-one, personalized assistance may improve upon previous strategies and help Medicare beneficiaries to select the most appropriate and economical plan. Pharmacists are potentially well-suited to provide this one-onone assistance to Medicare patients in the community. ${ }^{3}$ Indeed, the inclusion of pharmacists in the care of Medicare 


\section{American Journal of Pharmaceutical Education 2018; 82 (9) Article 6452.}

beneficiaries is economically beneficial from both beneficiaries' and plan sponsors' perspectives, as it is shown to reduce Medicare billings by as much as $12 \% .{ }^{16}$ Due to convenient hours of operation and a high level of trust in the profession, ${ }^{17,18}$ many beneficiaries may seek assistance from pharmacists during Medicare open enrollment to determine which plan is most appropriate. However, previous research has shown that over $50 \%$ of pharmacists are unable to correctly use the Medicare Plan Finder Tool. ${ }^{3,19}$ Training and engaging pharmacy students in the delivery of this service is a sustainable approach to address this deficit, and may further serve to familiarize Medicare patients with emerging pharmacy services.

Assisting Medicare beneficiaries in Medicare Part D plan selection requires pharmacy students to have knowledge about Medicare and confidence in using the online Medicare Plan Finder tool, as well as the ability to interpret the results of the tool. Guidance from trained pharmacy students able to identify appropriate plans using the Medicare Plan Finder Tool is shown to realize costsavings for Medicare beneficiaries; ${ }^{8}$ however, previous research has shown that less than half (47\%) of secondyear pharmacy students are able to identify appropriate Medicare Part D plans. ${ }^{3,20}$ Furthermore, students are hesitant to initiate counseling with Medicare beneficiaries, even though they believe that patients would accept such services from pharmacists. ${ }^{21}$ Because didactic and experiential learning can have a positive impact on students' confidence and readiness to provide services, ${ }^{3,22}$ there is a need to create a service learning program to prepare future pharmacists to effectively assist Medicare beneficiaries. Thus far, only one study, related to Medicare Part D program, has extended students' learning beyond classrooms. ${ }^{8}$ Patel and colleagues reported that, through statewide outreach events, students from six pharmacy schools in California reduced out-of-pocket costs among Part D beneficiaries. ${ }^{8}$ Our project departs from Patel and colleagues' program. ${ }^{8}$ First, by partnering with Alabama State Health Insurance and Assistance Program (SHIP), our program is offered by pharmacy student counselors trained and certified via the same examination materials used to certify SHIP volunteer counselors annually, which increases the program's credibility in the eyes of Medicare patients, health care providers, and Medicare plan advisors. Second, our program is expansive, covering multiple counties with a large number of students participating in the effort. Third, our program is sustainable and well integrated into the curriculum through commitment from both the school and SHIP.

Our Medicare Outreach Program was developed through collaboration between the Auburn University (AU) Harrison School of Pharmacy and an expert external agency (SHIP). Alabama SHIP, which is a partnership between the Administration for Community Living (ACL), the Alabama Department of Senior Services, and the Area Agencies on Aging, is the key public organization that offers free and unbiased assistance to Medicare beneficiaries throughout the year. ${ }^{23}$ During open enrollment period, SHIP coordinators have increased service demands and, as a result, rely heavily on certified volunteer counselors. The Medicare Outreach Program partnership was formed to help increase the capacity of qualified SHIP volunteers by training pharmacy students to serve as certified SHIP counselors.

The formation of community partnerships for outreach and learning is not unprecedented in pharmacy schools. Among schools with community partnerships, Roseman University has recently partnered with the Nevada State Health Insurance and Assistance Program and trained 20 students to offer assistance via telephone calls to Medicare beneficiaries. ${ }^{24}$ East Tennessee State University has partnered with TN SHIP, and two other Tennessee schools have followed suit. However, thus far, none of the existing programs have reported their experiences and outcomes.

The AU-SHIP Medicare Outreach Program, which was created in 2013 to prepare future pharmacists to assist Medicare beneficiaries in Part D plan selection, thus represents a unique didactic and experiential community partnership. The objectives here are to describe the inputs, outputs, and outcomes associated with the AU-SHIP Medicare Outreach Program, as well as lessons learned over four years of implementation. Implications for scaling of the program to other pharmacy schools will also be discussed.

\section{METHODS}

The objectives of AU-SHIP program events were to help Medicare beneficiaries in Medicare plan selection and to assess whether they qualified for low-income subsidy programs. To accomplish these objectives, the authors prepared student pharmacists to assist beneficiaries, planned events in community settings to increase access for beneficiaries, and evaluated the program to ensure that the goals were met. Table 1 lists resources that the program used to accomplish the set objectives. All procedures were approved by an expedited review at the primary author's institution.

The comprehensive Medicare training to prepare student pharmacists for the AU-SHIP Medicare Outreach Program can be described in two parts. The first part is integrated into Pharmacy Practice Development, Management and Evaluation I (PYDI 9210), which is a required course for second-year PharmD students. The second part 


\section{American Journal of Pharmaceutical Education 2018; 82 (9) Article 6452.}

Table 1. Resources Used to Implement Medicare Outreach Program (Annually)

\begin{tabular}{|c|c|}
\hline Resources & $\mathbf{n}$ \\
\hline Medicare-Specific Class Lectures & 4 (5 hours) \\
\hline Case-Based Group Activities & 1 (1 hour) \\
\hline Student Training \& Quiz Modules & 3 modules (85-86 questions) \\
\hline Pre-Event Student Orientation Session & 1 (2 hours) \\
\hline Coordinator for Student Course \& Program & 1 \\
\hline Graduate Research Assistant, 4 Months, $20 \mathrm{Hrs} / \mathrm{Wk}$ & 1 \\
\hline Community Event Venues $^{\mathrm{a}}$ & $10-17$ venues \\
\hline Event Laptops $^{\mathrm{a}}$, Wifi Hotspots ${ }^{\mathrm{a}}$, Printers ${ }^{\mathrm{a}}$, Office Supplies & $\begin{array}{l}\text { 4-6 stations/event (Supplied by SHIP, community } \\
\text { settings, or students' own computers) }\end{array}$ \\
\hline SHIP Supervisors/Event & $1-2$ \\
\hline \multirow[t]{2}{*}{ AU Supervisors/Event } & $1-2$ \\
\hline & Funding \\
\hline Graduate Research Assistant Stipend for 4 Months (Sept-Dec) & $\$ 1,500 /$ month per individual \\
\hline Event Mileage Reimbursement (2-3 Cars/Event) & $\$ 1,200-\$ 1,700 /$ year \\
\hline Printing, Copying, Stamp Costs For Flyers, Mailings & $\$ 200-\$ 300 /$ year \\
\hline
\end{tabular}

${ }^{a}$ Some community venues provided access to a computer laboratory

consisted of materials provided by AL SHIP as part of their standard SHIP counselor training.

In PYDI 9210, four 1.5-hour sessions presented Medicare-specific information, with an additional 25 minutes of online video tutorials (Table 1). Topics included: Overview of Medicare Parts A, B, and C (one lecture); Medicare Part D Prescription Drug Plans and Medication Therapy Management (two lectures); and Low Income Assistance Programs including Medicare Savings Programs and Extra Help (one lecture). Additionally, one session consisted of case-based and team-based group activities dedicated to using and interpreting results from the Medicare Plan Finder Tool. Also, student pharmacists, in groups of three to four, completed a homework assignment with multiple patient cases allowing them to use the Tool, interpret the results, and make recommendations.

To certify that students were prepared to volunteer at SHIP-sponsored events, they had to complete the second part of the training. Study materials and quizzes were provided by SHIP coordinators and offered online through the course learning management website. Quizzes consisted of multiple-choice questions and were the same as those used by AL SHIP for annual SHIP volunteer counselor certification. Overall, there were three quiz modules: Getting Started with Medicare Basics (38-39 quiz questions), Medicare Advantage Plans (22 quiz questions), and Medicare Part D Prescription Drug Coverage (25 quiz questions). On average, 46 pages of text provided by SHIP were available for review online prior to or during each quiz module. Students were given unlimited attempts to pass each module for four weeks from early September to early October. Those who passed all quizzes with a score of $80 \%$ or higher were eligible to attend AU-SHIP Medicare Outreach Events. Participation in this training was voluntary, although second-year students were incentivized with $0.5 \%$ bonus points in PYDI 9210 for completion of all three quiz modules, and students received an additional $1.5 \%$ bonus points for volunteering at an event. Students who passed all quiz modules and volunteered at one event were certified as SHIP counselors and received a paper certificate at the end of the course.

During 2013 and 2014, third- and fourth-year students were also encouraged to participate, with credit offered in the third-year Pharmacy Practice Experience course (PYDI 9490). A free alternative to AU's standard learning management system had to be used to administer the quizzes, which did not provide detailed scores. Also, due to difficulties in coordinating course and event schedules, only second-year and fourth-year students were included in 2015, and only second-year students were included in 2016.

One voluntary pre-event orientation was held in 2016. The purpose of this two-hour "boot camp" session was to familiarize students with event workflow and to provide further opportunity to practice using the Medicare.gov Plan Finder Tool through training cases supplied by SHIP. The session was held at a convenient time chosen by the majority of students and was facilitated by the course coordinator, a graduate research assistant (GRA), and a SHIP counselor.

Furthermore, the planning of AU-SHIP outreach events involved four parts. First, event funding was secured. The Harrison School of Pharmacy and Alabama Department of Senior Services (ADSS) were committed 


\section{American Journal of Pharmaceutical Education 2018; 82 (9) Article 6452.}

to implementation of the AU-SHIP Outreach Program. After the initial funding in 2013 from Auburn University to start the program, ADSS provided $\$ 8,000$ in direct costs to Auburn University each year to offer this joint program. This was used to fund one GRA for four months $(\$ 6,000)$, advertisement costs $(\$ 200-\$ 300)$, and mileage $(\$ 1200$ $\$ 1700$ ) for travel to event locations.

Second, event location and sign-up was planned. Each summer, locations, dates, and times of joint AUSHIP Medicare Outreach Events were scheduled via discussion between the course coordinator and the primary SHIP coordinator, with input from current pharmacy students. Travel time to event locations was limited to one hour each way. Events were arranged in morning and afternoon shifts, with four to eight volunteer slots per shift, resulting in about 70-80 opportunities. Once finalized, students signed up online and slots were then assigned on a first-come first-served basis. Students who wished to volunteer but were not able to find an open time slot were added to a waitlist by emailing the research assistant. Each year, one or two events were also planned but held in reserve; if there was high demand for additional time slots, these events were opened to the students.

Third, event advertisements were planned and conducted. The joint events were advertised through various mechanisms, including flyers in local libraries, pharmacies, and grocery stores; newspaper, Internet, and radio announcements; and an interview with a local radio station. Additionally, SHIP coordinators contacted the beneficiaries whom they had served in the past via phone and/or flyers. Beneficiaries were instructed to bring their Medicare cards, medication record or medication bottles, and list of gross monthly income to events.

Fourth, event workflow was planned. Medicare Outreach Events were held throughout Alabama at various community venues (eg, recreation center, senior center, Goodwill Career Center, etc.), each lasting two to six hours. Pharmacy students served one shift each for a period of at least two hours. Students were asked to carpool, and two to three vehicles were reimbursed for mileage per event (approximately \$1,200-\$1,700/year). During the event, students were assigned to one of three stations: intake, plan comparison, or exit interview. When beneficiaries arrived at the event, they were first seated at the intake station. In this one-on-one setting, students worked in pairs or alone to collect beneficiaries' Medicare and prescription information using a SHIP intake form. Students then escorted beneficiaries to the plan comparison station. There, students entered the data collected at the intake station into the Medicare Plan Finder Tool at Medicare.gov and compared PDP or Medicare-Advantage Prescription Drug (MA-PD) plans for the upcoming year. Under supervision by SHIP counselors and either the GRA or the PYDI course coordinator, students were able to advise beneficiaries regarding the most cost-effective plans and, if applicable, help them enroll in a new plan Beneficiaries made their own decisions regarding pharmacy selection and plan enrollment during this process. Upon completion of the plan comparison station, beneficiaries moved to the exit interview station. At this station, beneficiaries completed a satisfaction survey and students checked to ensure that all forms were completed.

\section{Outcome Evaluation}

In order to determine if the goals of this study were met, both beneficiary outcomes and student outcomes were evaluated. Following beneficiaries' decision to enroll or remain with the same plan, students administered a brief 17-item paper survey to record demographic information, plan costs, enrollment results, and satisfaction using multiple-choice and free response questions (Appendix 1). Reported outcomes included Medicare beneficiaries' plan cost savings and satisfaction. Cost-savings were calculated by comparing total annual cost of newly enrolled plans to the cost of the current plan in the upcoming year. Also, at the exit interview station, beneficiaries' satisfaction was assessed using a 5-point Likert-type scale ranging from "Strongly Disagree" to "Strongly Agree."

As for student outcomes, perceived changes in knowledge and attitudes were assessed by having students complete a paper or online survey (via Qualtrics) (Appendix 2). Student surveys consisted of two sections. The first section assessed students' confidence in knowledge and counseling abilities using a 5-point Likert-type scale ranging from "Greatly Decreased" to "Greatly Increased." In the second section, students were asked to complete an open-ended reflection of their experience.

Beneficiaries' and students' outcomes were analyzed using IBM SPSS Statistics version 22 software (IBM Corp, Armonk, New York), and student reflections were analyzed via realistic thematic analysis using ATLAS.ti 7.5.6 Qualitative Data Analysis software (ATLAS.ti Scientific Software Development GmbH, Berlin, Germany).

\section{RESULTS}

A total of 17, 10, 11, and 13 Medicare Outreach Events were held between October and December in 2013, 2014, 2015 and 2016, respectively. A total of 524 beneficiaries were served over the four year period, with the largest number (147) in the first year (Table 3). Beneficiaries' average annual predicted cost-savings after enrolling in a new plan (including PDP's or MA-PD's) were \$278.71 (2013), \$1,081.66 (2014), \$842.84 (2015), and 


\section{American Journal of Pharmaceutical Education 2018; 82 (9) Article 6452.}

$\$ 1,382.90$ (2016) (Table 4). Furthermore, over $90 \%$ of beneficiaries agreed or strongly agreed that they were satisfied with the assistance they received from volunteers at the event.

In 2013, there were 229 students who completed all three quiz modules. In the following years (2014-2016), there were 173, 120, and 112 students who also completed all three quiz modules, respectively (Table 2). Secondyear students comprised the largest number of participants, and average overall quiz scores were above $90 \%$ in all years. The number of students who were certified as SHIP counselors by passing the quiz modules and volunteering at one event declined in 2015 and 2016 compared to the first two years, with 110 students in 2013, 111 in 2014, 82 in 2015, and 89 in 2016 (Table 3). However, the proportion of eligible students (those who passed all quiz modules with a score of $80 \%$ or higher) who decided to volunteer at an event increased each year, from less than $50 \%$ in 2013 to nearly $80 \%$ in 2016 . Seventy-six students attended the optional pre-event orientation session in 2016.

Regarding students' attitudes after volunteering at a Medicare Outreach Event, 79 (2013), 75 (2014), 70 (2015), and 81 (2016) students completed the open-ended reflection portion of the survey. Detailed analysis of themes has been reported previously. ${ }^{25}$ The most frequently discussed issues after volunteering at an event included: aspirations for future participation, self-reported learning experience, ability to help patients, rewarding experience, realization of community need, and real-world application of class material.

Seventy-five (2014), 74 (2015), and 86 (2016) students completed the knowledge survey item. This question was not included on the student survey in 2013. In all years, a majority of students reported that confidence in their knowledge about Medicare and ability to help beneficiaries select Medicare Part D plans increased or greatly increased after volunteering (Table 4). Compared to other abilities, a greater proportion of students reported no change in their perceived ability to identify Medicare beneficiaries who might qualify for the ExtraHelp subsidy program.

\section{DISCUSSION}

Several reflections were drawn from the implementation of this student service program over four years. Importantly, student response to the Medicare Outreach Program was overwhelmingly positive in terms of participation and impact. Student participation was high, with over 80 students out of an annual class size of approximately 140 volunteering each year. Furthermore, the proportion of eligible students who volunteered at an event increased each year from 2013 to 2016, perhaps as a result of positive feedback from previous years' students. Consistent with previous studies, and keeping in mind a possible floor effect from our evaluation scale, student confidence in knowledge and ability to provide services to Medicare beneficiaries increased after completion of the program. ${ }^{3,20,26}$ Although students' pre-program knowledge was not assessed, self-reported changes in knowledge immediately post-program ensured that the experience remained timely and relevant. Future evaluation of student learning may focus on self-efficacy pre and post-program, utilizing a more nuanced scale to determine levels of change than used here. This will allow for targeted educational efforts to improve student selfefficacy, equipping students with the skills, confidence, and motivation needed to help Medicare beneficiaries in their communities after they graduate and become practicing pharmacists. Additionally, this program differs from many others ${ }^{3,8,20}$ in that it combines coursework with community outreach and it is offered in partnership with the Alabama SHIP to increase its legitimacy. As seen

Table 2. Student Pharmacist Medicare Outreach Training Quiz Modules Outputs and Outcomes

\begin{tabular}{lcccc}
\hline & $\mathbf{2 0 1 3}$ & $\mathbf{2 0 1 4}$ & $\mathbf{2 0 1 5}$ & $\mathbf{2 0 1 6}$ \\
\hline $\begin{array}{l}\text { Number Completed \& Passed Quiz }(\geq 80 \%)^{\mathrm{a}} \\
2^{\text {nd }} \text { year students }\end{array}$ & 124 & 120 & 112 & 112 \\
$3^{\text {rd }}$ year students & 100 & 53 & N/A & N/A \\
$4^{\text {th year students }}$ & 5 & 0 & 8 & N/A \\
$\quad$ Total & 229 & 173 & 120 & 112 \\
Quiz Score, Mean \% (Range \%) & & & & \\
$2^{\text {nd year students }}$ & $91.67(16.7-100)$ & $92.50(72.50-100)$ & $89.00(0-100)$ & $93.01(79.49-100)$ \\
$\quad$ Module 1 & $94.12(76.5-100)$ & $94.12(82.35-100)$ & $92.00(55-100)$ & $92.78(81.82-100)$ \\
$\quad$ Module 2 & $93.10(74.1-100)$ & $92.00(80.00-100)$ & $93(80-100)$ & $92.68(80-100)$ \\
$\quad$ Module 3 & 92.9 & 92.9 & 91.3 & 92.8 \\
$\quad$ Overall & & & & \\
\hline
\end{tabular}

${ }^{\mathrm{a} O u t}$ of an annual class size of approximately 140

${ }^{\mathrm{b}}$ Data not available for $3^{\text {rd }}$ or $4^{\text {th }}$ year students 


\section{American Journal of Pharmaceutical Education 2018; 82 (9) Article 6452.}

Table 3. Medicare Outreach Events Outputs

\begin{tabular}{lcccc}
\hline Outputs & $\mathbf{2 0 1 3}$ & $\mathbf{2 0 1 4}$ & $\mathbf{2 0 1 5}$ & $\mathbf{2 0 1 6}$ \\
\hline Number of Students Who Volunteered, N (\%) & $110(48.0)$ & $111(64.2)$ & $82(68.3)$ & $89(79.5)$ \\
Number of Beneficiaries Served & 147 & 121 & 122 & 134 \\
Number of Events (Counties) & $17(10)$ & $10(9)$ & $11(6)$ & $13(8)$ \\
\hline
\end{tabular}

${ }^{a}$ Students were eligible to volunteer if they passed the quiz with an overall score $\geq 80 \%$

in students' reflection comments, experiential education through community outreach helped prepare future pharmacists for real-world practice and increased their confidence and willingness to assist Medicare patients via realization of beneficiary cost-savings. ${ }^{8}$ This confidence and preparedness has been noted as a key target outcome of pharmacy education., ${ }^{3,22}$

Although the program's training course and scheduling logistics became more streamlined over four years, improvements can still be made in program implementation. For example, despite the training offered to students, they were often confused by the multiple paper forms used during the events, leading to unnecessary delays and incomplete forms in some cases. A solution may be to hold mandatory, rather than voluntary, orientation sessions for students prior to the events. These orientation sessions could specifically address the confusion seen at the past years' events. Students' perceived confidence in their knowledge and abilities generally increased after volunteering at an event, but less so for the ability to identify Medicare beneficiaries who might qualify for ExtraHelp. Future coursework and orientation sessions may incorporate more practice cases to help students identify income and resource limits for Medicare subsidy programs. Additionally, the program proved beneficial as a community service program, resulting in significant projected annual out-of-pocket savings for Medicare beneficiaries and beneficiary satisfaction. It must be noted, however, that predicted annual cost-savings for beneficiaries after enrolling in a new plan may not reflect actual health care expenditures in the following coverage year, and indeed do not reflect any clinical benefit/detriment experienced by beneficiaries as a result of plan switching. We also recognize that the program had little access to hard-to-reach Medicare beneficiaries. We will continue to work with ADSS to identify best practices in terms of effective advertisement in order to attract these hard-toreach Medicare beneficiaries to the events.

Furthermore, expansion of the program to involve third and fourth-year pharmacy students poses difficulties. Participation from fourth-year pharmacy students remained low throughout the first three years of the program; thus, fourth-year students were not invited to participate in the most recent program cycle. Furthermore, third-year students were not invited to participate in 2015 and 2016 due to low numbers of volunteers seen in the first two years and complexity in coordination. Participation in the Medicare Outreach Program would be beneficial for these students by keeping their skills and knowledge about Medicare up to date. Co-curricular activities or participation as part of student organization activities may be helpful in getting these students to participate in the Medicare Outreach program.

There are several implications for other pharmacy schools looking to implement this program. First, one should look for a community partner to increase legitimacy. ${ }^{24}$ We partnered with ADSS and SHIP. This organization has experience and is known for providing Medicare enrollment events in the community, and employs staff who are experts in the nuances of subsidy programs, Social Security, and income and resource limits as they apply to Medicare plans. Since health insurance is so complex, pharmacy schools will benefit from a similar partnership. The SHIP organization is nationwide, but may have different names depending on the state. Second, events may be held in one or two local communities if funding or a partner cannot be secured. This will help to reduce costs, especially mileage reimbursement. Use of more advanced students or student organizations may also help with logistics (event sign-up, relaying of messages, supervision at events, etc.). Third, the program may be integrated into various course requirements. We offered bonus points in class to incentivize a large number of students to participate, but integration into introductory/ advanced practice pharmacy experiences (IPPE/APPE's) or skill labs may be preferred at some institutions. Although we used faculty and guest lecturers, peer-to-peer presentations may also be effective and affordable. ${ }^{19,27}$

\section{CONCLUSION}

The joint AU-SHIP partnership and Medicare Outreach Program is highly successful and may be applied in other pharmacy schools. The collaboration between Auburn University and SHIP resulted in the education and financial assistance of many elderly and disabled individuals in Alabama. Furthermore, future pharmacists gained an understanding of Medicare Part D that will allow them to better assist their patients. The program is now 
American Journal of Pharmaceutical Education 2018; 82 (9) Article 6452.

Table 4. Medicare Outreach Events Outcomes

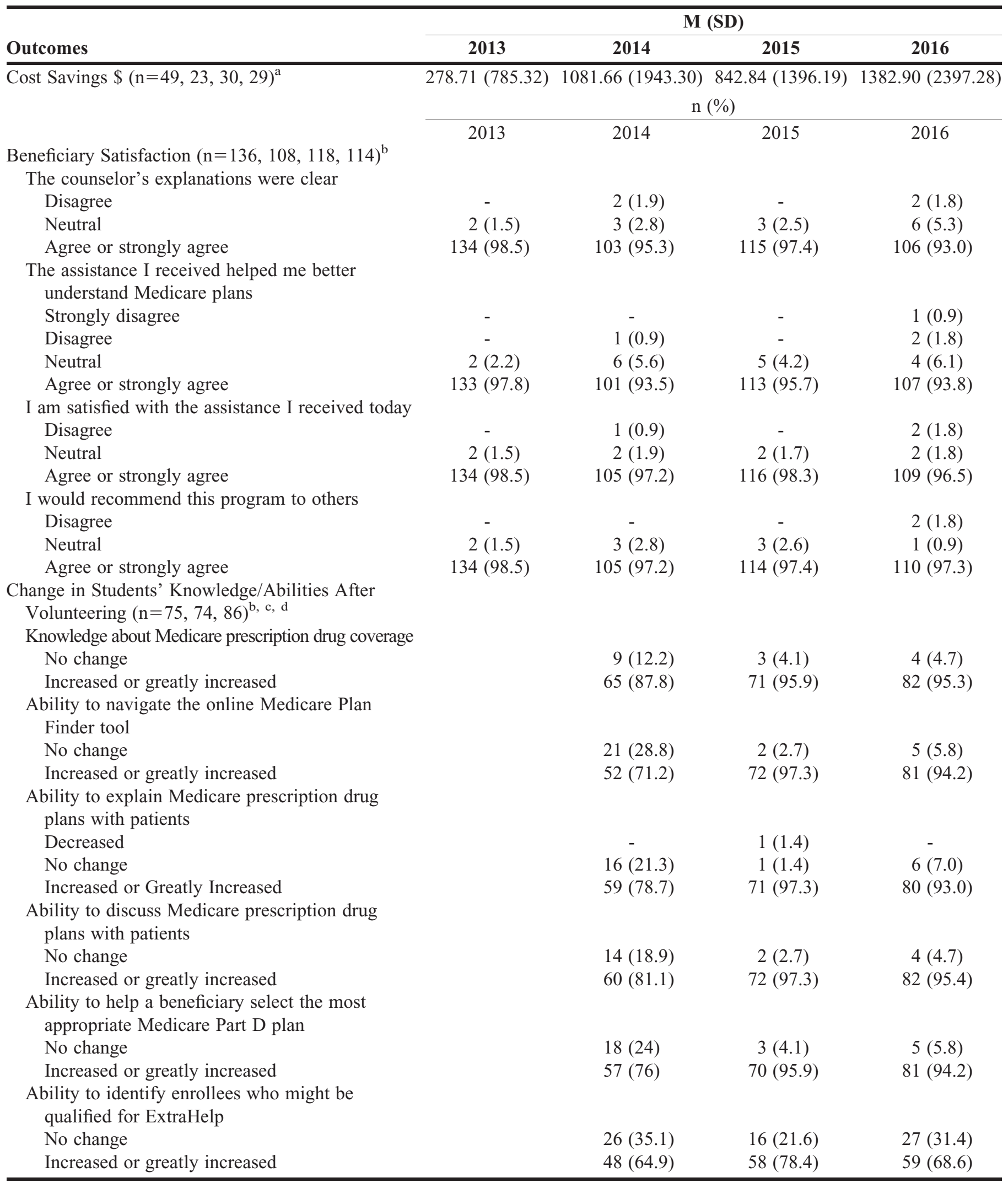

aPredicted savings for beneficiaries' who enrolled in a new prescription drug plan (PDP) or Medicare Advantage plan (MA-PD)

${ }^{\mathrm{b}}$ Percentages may differ due to item non-response

"No individuals reported "Greatly decreased" and only one individual reported "Decreased"

${ }^{\mathrm{d}}$ Not assessed in year 2013 


\section{American Journal of Pharmaceutical Education 2018; 82 (9) Article 6452.}

sustained, as ADSS has built funding into their annual budget, and training is built into the school curriculum.

\section{ACKNOWLEDGMENTS}

The authors would like to acknowledge the Alabama Department of Senior Services and Auburn University Outreach Program for their support in funding this program. We also would like to acknowledge our collaborators at ADSS and SHIP: Robyn James, Sharon Jalieba, Misty Barnes, Dawn Glascock and Jan Neal; the program would not be successful without this partnership. Neither the sponsors nor our collaborators played any role in manuscript preparation.

\section{REFERENCES}

1. Kaiser Family Foundation. The Medicare Part D prescription drug benefit. 2016; http://kff.org/medicare/fact-sheet/the-medicareprescription-drug-benefit-fact-sheet/. Accessed April 21, 2016. 2. Hoadley J, Cubanski J, Hargrave E, Summer L. Medicare Part D: a first look at plan offerings in 2015. 2014. http://kff.org/medicare/ issue-brief/medicare-part-d-a-first-look-at-plan-offerings-in-2015/. 3. Galal SM, Patel RA, Thai HK, et al. Impact of an elective course on pharmacy students' attitudes, beliefs, and competency regarding Medicare Part D. Am J Pharm Educ. 2012;76(5):Article 91.

4. Uhrig JD, Harris-Kojetin L, Bann C, Kuo TM. Do content and format affect older consumers' use of comparative information in a Medicare health plan choice? Results from a controlled experiment. Med Care Res Rev. 2006;63(6):701-718.

5. Perry M, Dulio A, Cubanski J. Voices of beneficiaries: Medicare Part D insights and observations one year later. 2006. https:// kaiserfamilyfoundation.files.wordpress.com/2013/01/7605.pdf. 6. Cline RR. Prescription drug insurance choices: more answers, further questions. Res Social Adm Pharm. 2008;4(3):183-185.

7. Wellman GS, Vidican C. Pilot study of a hierarchical bayes method for utility estimation in a choice-based conjoint analysis of prescription benefit plans including medication therapy management services. Res Social Adm Pharm. 2008;4(3):218-230.

8. Patel RA, Lipton HL, Cutler TW, Smith AR, Tsunoda SM, Stebbins MR. Cost minimization of medicare part d prescription drug plan expenditures. Am J Manag Care. 2009;15(8):545-553.

9. Keenan TA. Prescription drugs and Medicare Part D: a report on access, satisfaction, and cost. 2007. http://assets.aarp.org/rgcenter/ health/rx_medicared.pdf.

10. Federman AD, Safran DG, Keyhani S, Cole H, Halm EA, Siu AL. Awareness of pharmaceutical cost-assistance programs among inner-city seniors. Am J Geriatr Pharmacother. 2009;7(2):117-129. 11. Kuye IO, Frank RG, McWilliams J. Cognition and take-up of subsidized drug benefits by medicare beneficiaries. JAMA Intern Med. 2013;173(12):1100-1107.
12. Peters E, Dieckmann N, Dixon A, Hibbard JH, Mertz CK. Less is more in presenting quality information to consumers. Med Care Res Rev. 2007;64(2):169-190.

13. Barnes AJ, Hanoch Y, Rice T. Determinants of coverage decisions in health insurance marketplaces: consumers' decisionmaking abilities and the amount of information in their choice environment. Health Serv Res. 2015;50(1):58-80.

14. McCormack LA, Burrus BB, Garfinkel SA, Gibbs D, HarrisKojetin LD, Sangl JA. Providing information to help medicare beneficiaries choose a health plan. J Aging Soc Policy. 2001; 12(2):49-72.

15. Harris-Kojetin LD, Uhrig JD, Williams $\mathrm{P}$, et al. The "choose with care system" - development of education materials to support informed medicare health plan choices. J Health Commun. 2007; 12(2):133-156.

16. MacLaren R, Bond CA, Martin SJ, Fike D. Clinical and economic outcomes of involving pharmacists in the direct care of critically ill patients with infections. Crit Care Med. 2008; 36(12):3184-3189.

17. Donohue JM, Huskamp HA, Wilson IB, Weissman J. Whom do older adults trust most to provide information about prescription drugs? Am J Geriatr Pharmacother. 2009;7(2):105-116.

18. Bearden DT, Holt T. Statewide impact of pharmacist-delivered adult influenza vaccinations. Am J Prev Med. 2005;29(5):450-452. 19. Stebbins MR, Cutler TW, Corelli RL, Smith AR, Lipton HL. Medicare Part D community outreach train-the-trainer program for pharmacy faculty. Am J Pharm Educ. 2009;73(3):Article 53.

20. Cutler TW, Stebbins MR, Lai E, Smith AR, Lipton HL. Problembased learning using the online medicare part d plan finder tool. Am. J. Pharm. Educ. 2008;72(3):47.

21. Urmie JM, Farris KB, Herbert KE. Pharmacy students' knowledge of the Medicare drug benefit and intention to provide medicare medication therapy management services. Am J Pharm Educ. 2007;71(3):Article 41.

22. Kuhn C, Powell PH, Sterrett JJ. Elective course on medication therapy management services. Am J Pharm Educ. 2010;74(3):Article 40.

23. The State Health Insurance Assistance Program National Technical Assitance Center. About us. 2014. https://www. shiptacenter.org/about-us/. Accessed April 21, 2016. 24. Usufzy P. Pharmacy students volunteer to answer callers' Medicare questions. Las Vegas Review-Journal. 2016.

25. Hollingsworth JC, Teeter BS, Westrick SC. Evaluation of student outcomes after participating in a Medicare outreach program. $J$ Higher Educ Outreach Engage. 2015;19(2):139-154.

26. Zagar M. Preparing PharmD students to participate in Medicare Part D education and enrollment. Am J Pharm Educ. 2007;71(4): Article 77.

27. Lipton HL, Lai CJ, Cutler TW, Smith AR, Stebbins MR. Peer-topeer interprofessional health policy education for Medicare Part D. Am J Pharm Educ. 2010;74(6):Article 102. 


\section{American Journal of Pharmaceutical Education 2018; 82 (9) Article 6452.}

Appendix 1. Medicare Plan Selection Assistance Program

\section{Part I. Participant Demographics}

Age:

Sex: Male Female

Race: White Black/African American Asian Other

Ethnicity: Hispanic Non-Hispanic

Monthly gross income:

Do you have access to a computer and Internet? Yes No

During open enrollment last year (2014), did you compare different prescription drug plans before selecting which plan to enroll in? Yes No Don't know N/A, I am new to Medicare

Before today, have you ever received assistance with plan selection from anyone or any agency?

Yes: From whom? Check all that apply:

Doctors' clinic Pharmacy State Health Insurance Assistance Program Family, friends, co-worker Other:

No

Don't know

\section{Part II. Online Medicare Plan Finder Tool}

The online Medicare Plan Finder tool allows you to compare and select Medicare Part D and Medicare Advantage plans on www. medicare.gov at no charge. Are you aware of this online tool?

Yes: Have you used it?

Yes: Go to Question 10

No: Go to Part III

No: Go to Part III

Based on your experience with the online plan finder tool, how much do you agree or disagree with the following statement? Check the appropriate box (5-point Likert scale from strongly disagree to strongly agree)

The online tool is easy to use.

The language used by the tool is easy to understand.

The plan results are easy to interpret.

Part III. Results - For Student Pharmacists to Complete

Is the beneficiary currently enrolled in any subsidy program?

No

Yes: circle one QMB SLMB QI LIS/ExtraHelp

Possible qualified for one and have filled out/will fill out an application:
circle one
QMB
SLMB
QI LIS/ExtraHelp

Do you currently have prescription drug coverage through Medicare?

Yes: MA-PD: Annual cost of current plan in 2016 (drug portion only):

PDP: Annual cost of current plan in 2016:

No: Pay out-of-pocket

Have other insurance

Plan comparison:

PDP: Overall cost of least expensive plan:

OR Did not compare PDP plans

MA-PD

Cost of least expensive plan (drug portion only):

OR Did not compare MA-PD plans

What is the beneficiary's decision to enroll?

Decided to stay with the status quo (what they currently have): Go to Part IV

Has not decided: Go to Part IV

Picked a new plan but has not enrolled yet

Signed up for a new plan

What type of plan was chosen, and what is the annual cost?

MA-PD: Cost (drug portion only): 


\section{American Journal of Pharmaceutical Education 2018; 82 (9) Article 6452.}

PDP: Overall cost:

Why did you choose this plan? (eg, overall least expensive, no deductible, low monthly premium, etc.)

\section{Part IV. Your Evaluation of the Assistance You Received}

The counselor was using the Medicare online tool to evaluate Medicare plans. How much do you agree or disagree with the following statements? Check the appropriate box (5-point Likert scale from Strongly Disagree to Strongly Agree)

I can use the tool without any assistance.

I can understand the language used by the tool without any assistance.

I know what the results mean without any assistance.

To what extent do you agree or disagree with the following statements? (5-point Likert scale from Strongly Disagree to Strongly Agree).

The counselor's explanations were clear.

The assistance I received helped me better understand Medicare plans.

I am satisfied with the assistance I received today.

I would recommend this program to others.

Appendix 2. Medicare Open Enrollment Event - Student Reflection

Instructions. Please answer the following questions. Your response is very important in helping us improve the program in the future.

Medicare prescription drug coverage can be provided through both MA-PDs and PDPs. Thinking back to before you volunteered, how would you say each of the following has changed now that you have volunteered at a Medicare Open Enrollment event? (5-point Likert-type scale with response options including: Greatly Decreased, Decreased, No Change, Increased, Greatly Increased).

Knowledge about Medicare prescription drug coverage?

Ability to navigate the online Medicare Plan Finder tool

Ability to explain Medicare prescription drug plans with patients

Ability to discuss Medicare prescription drug plans with patients?

Ability to help a beneficiary select the most appropriate Medicare Part D plan?

Ability to identify enrollees who might be qualified for Extra Help?

In one paragraph or more, please reflect on your experience volunteering at a Medicare Open Enrollment event: 